\title{
ACQUIRED DOUBLE PYLORUS PRESENTING AS A GASTROINTESTINAL BLEEDING
}

Sarra Laabidi ${ }^{1}$, Asma Ben Mohamed ${ }^{2}$, amal khsiba ${ }^{3}$, Manel Yakoubi ${ }^{2}$, Moufida Mahmoudi $^{2}$, Mouna Medhioub ${ }^{2}$, Lamine Hamzaoui ${ }^{2}$, and Mohamed Msaddak Azzouz ${ }^{2}$

${ }^{1}$ University of Tunis El Manar

${ }^{2}$ Mohamed Tahar Maamouri Hospital

${ }^{3}$ Mohamed Taher Maamouri Hospital

January 24, 2022

\begin{abstract}
Gastroduodenal fistula (GDF) is a rare endoscopy finding that can be acquired or congenital. We present the case of a 65year-old male without medical past history who was admitted for gastrointestinal bleeding secondary to peptic ulcer. The case shows an acquired double pylorus, due to pre pyloric ulcer.
\end{abstract}

\section{Hosted file}

DP1 (2).pdf available at https://authorea.com/users/456882/articles/553840-acquired-doublepylorus-presenting-as-a-gastrointestinal-bleeding
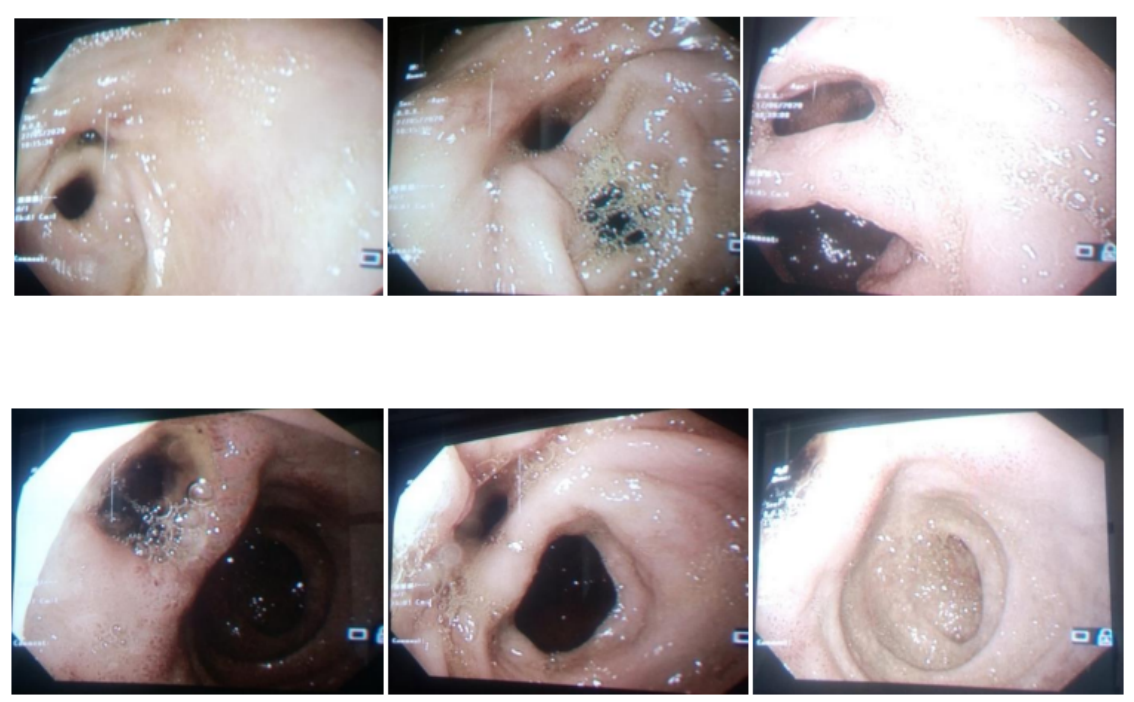